\title{
Direct-to-consumer genetic testing: where and how does genetic counseling fit?
}

\begin{abstract}
Direct-to-consumer genetic testing for disease ranges from well-validated diagnostic and predictive tests to 'research' results conferring increased risks. While being targeted at public curious about their health, they are also marketed for use in reproductive decision-making or management of disease. By virtue of being 'direct-to-consumer' much of this testing bypasses traditional healthcare systems. We argue that direct-toconsumer genetic testing companies should make genetic counseling available, preas well as post-test. While we do not advocate that mandatory genetic counseling should gate-keep access to direct-to-consumer genetic testing, if the testing process has the potential to cause psychological distress, then companies have a responsibility to provide support and should not rely on traditional healthcare systems to pick up the pieces.
\end{abstract}

First draft submitted: 9 January 2017; Accepted for publication: 3 March 2017; Published online: 11 May 2017

Keywords: CHIP ME • connecting science $\bullet$ direct-to-consumer $\bullet$ DTCGT $\bullet$ genetic counseling $\bullet$ genetic test $\bullet$ genomics $\bullet$ website

\section{Setting the scene}

There are many perceived benefits of directto-consumer genetic testing (DTCGT). For countries that do not have established clinical genetics services already, there will be public who are only able to receive diagnostic or predictive genetic results via DTCGT [1] . If clinical utility and validity can be assured, then such results may indeed empower individuals to be more aware of the health problems that could affect them or their children and to take proactive steps in disease management or prevention. However, there remains concern regarding the utility and validity of many direct-to-consumer (DTC) tests [2].

A DTCGT company may reveal pertinent results quicker than healthcare services blighted by long waiting lists, and since results are delivered direct to the customer, they do not necessarily have to be entered into medical records, which may be preferable for those with specific privacy concerns.

However, amid the enthusiasm surrounding DTCGT, there has also been extensive debate and criticism covering scientific, clinical, ethical and legal issues [3,4]. The clinical validity and utility of certain tests, especially those for complex traits, have also been continuously questioned [2,5]. Many DTC companies lack involvement of clinically trained and regulated healthcare scientists or health professionals [6], and questions have been raised about the adequacy of consent processes [7] both in terms of informed choice and for secondary use of data for research by third parties $[8,9]$. Recent research also suggests that customers often need help to interpret their DTC personal disease risks correctly [10]. If customers are left confused or anxious by their results and are unable to receive adequate information and support from the DTCGT company themselves, then there is evidence to suggest they seek access to established healthcare services [11]. Such services, particularly if publicly funded, for example, National Health Service in the UK, do not necessarily have the resources to welcome DTC customers [12] and fear that valuable time will be spent explaining complex results that may have limited validity or for which no health management can be
Anna Middleton*,1, Álvaro Mendes², Caroline M Benjamin $^{3,4}$ \& Heidi Carmen Howard 5

'Society \& Ethics Research Group, Connecting Science, Wellcome, Genome Campus, Cambridge, UK ${ }^{2}$ UnIGENe \& Centre for Predictive \& Preventive Genetics (CGPP), IBMC Institute for Molecular \& Cell Biology, i3S - Instituto de Investigação e Inovação em Saúde, Universidade do Porto, Portugal

${ }^{3}$ School of Community Health \& Midwifery, University of Central Lancashire, Preston, UK

'Liverpool Women's NHS Hospital Trust, Liverpool, UK

${ }^{5}$ Centre for Research Ethics \& Bioethics, Uppsala University, Uppsala, Sweden *Author for correspondence:

Anna.middleton@wgc.org.uk 
offered [13]. Actual impact on healthcare services is not understood though, and it is still unknown whether the fear of impact is greater than the reality. In healthcare systems that are willing to see DTCGT customers, there is the potential for needless follow-up screening, based on limited efficacy, just because the customer is anxious [14]. There is also limited evidence to suggest that, on receipt of genetic risk results, people actually modify their lifestyle behaviors [15]. However, at the same time, there is always the potential that results are gleaned which, on an individual basis, are genuinely helpful in terms of health management or personal decision-making.

While some DTCGT companies require a healthcare professional (not necessarily a genetics expert) to order the test and/or to return results, other companies deliver genetic test results directly to the customer, usually via an online portal. Many customers report no long-term psychological distress from their results [16] and indeed many results, particularly from SNP-based, genome-wide studies are not clearly linked to disease. However, some customers have reported extreme anxiety and distress after receiving predictive cancer results and have found the information and support offered by the DTCGT company to be severely lacking [17].

When DTCGT companies first came onto the market, there were concerns that the public would access services that 'should' remain under the control of clinicians [18,19]; it was implied that clinicians were putting unnecessary and paternalistic barriers in the way of access [20]. However, over time, there has been recognition that there are members of the public who, on receipt of disease risk results, would actually welcome the opportunity to talk these through with a suitably trained health professional [21]. Some commercial companies now do indeed offer 'genetic counseling' as part of their testing package.

The involvement of a healthcare professional, as part of the DTCGT pathway, varies considerably between companies [22]. As such, there have been repeated calls for DTCGT companies to provide more consistent and a higher level of pre- and posttest counseling from appropriately qualified health professionals [12,23-25]. Most recently, the American College of Medical Genetics has advised "A genetics expert such as a certified medical geneticist or genetic counsellor should be available to help the consumer determine, for example, whether a genetic test should be performed and how to interpret test results in light of personal and family history" [26]. Customers who do indeed seek out the services of a genetic counselor, post-DTCGT results, find this helpful in terms of informational content and support [27].
The focus of this perspective is on the provision of genetic counseling by DTCGT companies. We explored this by examining information provided by DTCGT companies on genetic counseling: what they write about it, if they offer it, and if so, how? As authors who are based in Europe, we have the European context of genetic counseling particularly in mind, and this Perspective is viewed via a European lens.

\section{What is genetic counseling?}

Although the classic definition of genetic counseling, as proposed by the American Society of Human Genetics in 1975 [28], has evolved over time, genetic counseling is still consistently described by professional bodies around the world as a client-centered communication process, designed to help people understand and adapt to the medical and psychosocial consequences of either having, being at-risk from or passing on a genetic condition [29-32]. Despite recent discussion about whether the scope of genetic counseling practice accurately reflects the current ethos of the profession [33], it is generally accepted that professionals such as medically trained clinical geneticists and genetic counselors and genetic nurses perform the genetic counseling process, as defined above [34]. These professionals are typically trained to prepare clients for genetic testing, explain results and attend to their client's needs with information gained from genetic tests.

Genetic counselors have expertise in the management of genetic disease, what screening is appropriate, and more recently they are becoming skilled in variant interpretation. They can explain to a patient the difference between a variant of uncertain significance and a pathogenic variant, and many are able to challenge whether a supposedly pathogenic variant does indeed fit the clinical phenotype [35]. Thus, their clinical knowledge forms part of the genetic counseling process.

Genetic counselors are also the healthcare professionals who primarily focus on the psychosocial and family communication issues that may arise from genetic (i.e., shared) information. In Europe, some countries offer an European Society of Human Genetics (ESHG)-approved training program or an MSc in genetic counseling [32]. A certification/ registration scheme is supervised by the ESHG, typically requiring 2 years of clinical practice as a genetic counselor post-training plus the completion of a professional portfolio of work, assessed at Master's level, to demonstrate competency to practice as dictated by the relevant board [32]. Many of these bodies provide a regulatory role in monitoring patient safety and ensuring the quality of their registrants in practice. 
The delivery of genetic counseling

Historically, genetic counseling practice has relied upon models from medicine, education and mental health [36]. A person-oriented approach was proposed by Kessler in 1997 as a blend of the teaching and counseling models which are commonly touted as central tenets of practice [37]. While the first emphasizes education and the provision of information, the counseling model enables an iterative and client-led discussion about the impact and use of this information.

In Europe, as in many places around the world, the delivery of genetic counseling is often performed face-to-face, with a small proportion via telephone or via video conferencing [38,39]. Communication is established via a two-way dialogue, where the counselor can hear the client's story and interact with them, in real time, to explain information and help find solutions for management together. After the counseling experience, it is common for genetic counselors to signpost clients to written material or to write a personalized summary letter [40]. Genetic counseling is thus not a simple one-way process where the client is invited to listen to or read material or watch a video. This latter service would be considered science communication or education and is neither client centered (one of the pivotal tenants of genetic counseling) nor designed for dealing with the immediacy of potential psychological distress.

\section{Genetic counseling within the DTCGT market} The ESHG recommends that commercial DTCGT companies provide face-to-face independent genetic counseling; such a service needs to be delivered by an appropriately trained professional [23]:

"Genetic counseling is the process through which information enables individuals to make their own free decisions about testing. A website cannot replace appropriate pre-test and post-test genetic counseling, which usually involves a face-to-face consultation with a knowledgeable professional" [23].

"DTC genetic testing and the advertisement of genetic tests of unproven benefit or without adequate independent genetic counseling are in opposition to the professional standards the ESHG sustains" [23].

In 2010, a review of 38 DTCGT company websites revealed that "many of the companies offering genetic testing services via the internet do not include genetic counseling at all in their services. Only a few urge customers to involve an expert before purchasing a gene test, and 'counseling' in most cases only is provided as written information via mail or via web-log" [41], in other words, it is not 'genetic counseling'. In 2013, a discourse analysis of DTCGT websites explored the way 'genetic counseling' was represented; this revealed that of 20 (mostly US-based) companies offering DTC genetic testing, 14 did not provide genetic counseling; of the six that did, none of this was offered face to face and ranged from 'genetics education' through to 'lifestyle/health advice' [25].

\section{What are DTCGT companies offering?}

In researching the current DTCGT climate for this article, we reviewed website content from commercial DTCGT companies. A convenience sample of six companies was identified via an Internet search (using two search engines, Google and DuckDuckGo, with the terms 'direct-to-consumer genetic test' in August and September 2016; these were reviewed again in December 2016). Ignoring companies offering only ancestry or nutritional testing, we focused on companies offering some level of healthrelated genetic testing that could be seen in Europe and members of the public in Europe could choose to seek out. The websites of DTCGT companies that we have explored are mostly from North America as well as from Europe. However, as the web heeds no geographical boundaries and customers from Europe have access to websites from North America (and vice versa), we have explored DTCGT websites irrespective of where the company is based.

Content of company websites was perused for information on 'genetic counseling'. We particularly wanted to know if genetic counseling was offered to customers and if so, in what manner. The process of website content evaluation was based on expert evaluation of written material - reading the content and assessing whether this described the offer of 'genetic counseling' and if so, what this comprised. Furthermore, we explored whether this appeared to align with the profile of genetic counseling as described by relevant bodies such as the American College of Medical Genetics and Genomics, European Society of Human Genetics and the Genetic Counsellor Registration Board in the UK and Republic of Ireland. The intent of this was to gauge an impression of what services were on offer and whether genetic counseling as described by DTCGT companies stands up to the standards set by expert groups. The website review was exploratory in nature and intended to provide us with an impression as opposed to a rigorous and systematic evaluation. We suggest this approach should be considered as a pilot work from which more methodologically robust research in the future can be built. This article is written from our perspective; it does not pretend to be an empirical research study, but rather an opinion piece that includes limited empirical data. 
Based on the review of websites from six DTCGT companies, we found that the description of genetic counseling services varied; there was no consistency across companies. We are unable to infer the actual delivery of service as we were only able to view the description of the delivery as stated in the website content. While we scrutinized the websites as much as possible, we accept that we may have missed information in the small print. However, our observations are based on what was obvious and clearly visible to readers and if we were members of the public, this is likely to be what they would view too. The following is a broad overview of our observations.

No mention of genetic counseling

One DTCGT company offered no information about genetic counseling nor any reference to interactions with health professionals. The website notes that information about genetic tests is "adequately presented in an understandable and transparent manner, so it does not require interpretation by third parties" [42]. The company explains that "After the completed analysis you will receive personalized advice based on your genetic predispositions in form of a personal guidebook either as a hard copy or as a print ready PDF file" [43]. The website also states that customers should look for further appropriate medical advice to inform important personal and medical decisions, without, however, mentioning genetic counseling: "you should consult an appropriate professional for advice, which would be specific in terms of your particular situation" [44].

\section{Reference to external genetic counseling services} One company that does not offer genetic counseling as part of their service delivery suggests that customers could seek genetic counseling from external services. 23andMe includes links to certified genetic counseling bodies/societies where customers can seek specialized help from genetic counselors (e.g., National Society of Genetic Counsellors [45]): "We encourage you to talk to a genetic counselor, a health professional with special training in genetic conditions, prior to collecting your sample for testing to learn more so you can make an informed decision about whether testing is right for you" [46]. It is worth mentioning that European customers are unlikely to be able to easily access the services of American Genetic Counselors based in the USA.

On the 23andMe site available to British customers it offers 'counseling resources' to customers and provides a link to the Association of Genetic Nurses and Counsellors, the Dutch Association of Genetic Counsellors, Swedish Society of Medical Genetics, Finnish Society of Medical Genetics and Danish Society of Medical
Genetics. This implies that by contacting these organizations the customers can access genetic counseling support. However, specifically for the British customers it is not possible to see a genetic counselor simply by contacting the Association of Genetic Nurses and Counsellors nor by contacting any of the regional clinical genetics services directly. Due to the nature of the publicly funded National Health Service, referral for genetic counseling is usually possible via specific routes, for example, through a General Physician or a hospital specialist. So, while the impression is given by 23andMe that it is easy to seek out a genetic counselor, the reality is somewhat different.

Health professional advice available

One company [47] offered advice from health professionals stating that 'a genetic consultation' is offered as part of their service. On review of what is actually offered, in our opinion, the type of service provided is not actually the process of genetic counseling as endorsed by European professional bodies such as the Genetic Counsellor Registration Board [48] and the ESHG [49]. The genetic tests that are advertised "include a medical consultation with a specialist," not specifying the type of professional involved nor if they are trained in genetic counseling and board certified/ registered. Also, the wording of the website suggests this service is exclusively information based: "Before you order you will be able to talk with one of our advisors who will talk you through what these tests can and cannot deliver for you. All our tests include a consultation with one of our trained medical doctors. He/She will guide you through your report and advise you the steps to take to live a happier healthier life" [50]. The service is offered either remotely (by phone) or face to face in one of the company's clinics.

\section{Post-test genetic counseling offered only}

Three companies offer genetic counseling upon request by the customer. In these cases, there is suggestion in the website that this possibility is specifically for post-test scenarios only, as it is directed to "explain/help understand your results," "to plan for next steps," or explicitly if results indicate a carrier test result: "During your scheduled appointment, our genetic counselors will review your report with you to help you understand your results, as well as discuss your potential next steps"; "If your results indicate that you are a carrier for a condition tested, Gene by Gene offers complimentary genetic counseling" [51]. While some companies do not specify how counseling was offered, others specifically mentioned the offer by phone: "a complimentary call with one of our genetic counselors to review your results upon request 
(currently applies to the USA only)" [52]. None of the four companies we reviewed, which offered post-test genetic counseling, appeared to be explicitly available to non-USA-based customers.

\section{Discussion}

We conclude that most of the company websites we viewed mention the need for some form of healthcare counseling; a subset specifically mentions the process of genetic counseling; and none actually describe what they offer in a way that concurs with recommended standards of genetic counseling (i.e., both pre- and post-test counseling) and is available to European customers.

Drawing our conclusions based on experience as well as the limited empirical data we have presented here, we feel there is an urgent need for private companies selling genetic testing DTC to consider their delivery of care. They should also provide clarity regarding the services they offer or recommend, specifically when discussing the genetic counseling process. If DTCGT companies offer health-related genetic testing that requires genetic counseling in the traditional healthcare setting, then why should it be accepted that companies sell them without both pre- and post-test genetic counseling? If genetic testing is offered, adequate counseling should be available with respect to the nature and potential impact of the test.

If DTCGT companies do indeed intend to offer genetic counseling, then this should align with professional genetic counseling body recommendations (and should be clear on their websites). Genetic counseling, as described by the ESHG [49], is a process that is delivered by appropriately trained and regulated professionals. It would be very helpful if websites could clearly explain what genetic counseling is and what it can offer.

One striking aspect of the services offered by the DTCGT companies we explored is the lack of pretest genetic counseling. This is in contrast to DTCGT recommendations by the ESHG [23], American College of Medical Genetics and Genomics [26] and the UK Human Genetics Commission [53], which state that pretest genetic counseling and psychosocial support should be offered as part of the testing process. Indeed, a key aspect of providing a quality counseling service is to help clients discuss all options in advance of making their final decisions to proceed or not. While it is clearly unnecessary for 'recreational' genetic testing, this becomes more pertinent for diagnostic, predictive or carrier testing for serious, potentially life-threatening conditions.

We acknowledge that information about genetic testing can be communicated in many ways to customers. Written and video materials full of informational content are very helpful. However, such information should not, in any way, be labeled or implied to be 'genetic counseling' or give the impression that this is a substitute for psychosocial support. Authentic genetic counseling is a two-way dialogue, where the counselor can hear the client's story and interact with them, in real time, to support them and help find solutions together.

What is key here is that customers may not be able to anticipate their psychological needs until they obtain a result that causes them anxiety. We also know that people who have genetic testing may not be able to identify psychosocial issues as effectively as they are able to recognize the need for information or explanation [54].

Although, of course, the provision of information stands as a key element in the genetic counseling process, studies suggest the crucial need to adapt the information to previous knowledge and existing beliefs of patients, as a way to enhance their understanding while integrating it with intra- and inter-personal characteristics [55,56]. While DTCGT companies commonly offer information about the tests being sold, there are limited grounds on how to make sure the information is fully understood by the customer and adequately accommodated in their wider life circumstances (namely, in terms of psychosocial wellbeing and the communication of risk information to relevant at-risk family members).

While we do not advocate that mandatory genetic counseling should gate-keep access to all DTCGT, we do suggest that it is mandatory to clearly explain in the companies' websites what the role of genetic counseling is and make it easily available, pre- as well as post-test, by appropriately trained and regulated genetic health professionals, so that at any point in the process of testing, customers have someone to turn to if needed. We also strongly suggest that when the term 'genetic counselor' or 'genetic counseling' is used, there is clear evidence of the professional qualifications, training and certification that professionals have, together with a clear description of what genetic counseling is and can offer. Given that the Web has no geographical boundaries, DTCGT companies should also spell out exactly which webbased customers can access services and whether these are only available in certain countries or not. It is also potentially negligent to suggest that customers can 'contact their local genetic counselor' when there are no mechanisms to actually do this in reality. It is also negligent for companies to offer testing that raises anxiety among their customers and then expect other healthcare services to pick up the pieces. 
Table 1. Direct-to-consumer genetic testing companies and genetic counseling services.

\begin{tabular}{|c|c|c|c|c|c|}
\hline Company & $\begin{array}{l}\text { Country as stated by } \\
\text { the address provided } \\
\text { on the website }\end{array}$ & Access date & $\begin{array}{l}\text { Healthcare } \\
\text { professional } \\
\text { involved? }\end{array}$ & Mention of GC & Ref. \\
\hline \multicolumn{6}{|c|}{ 1. No mention of GC } \\
\hline $\begin{array}{l}\text { Gene } \\
\text { Planet }\end{array}$ & $\begin{array}{l}\text { Slovenia (with } \\
\text { laboratories in } \\
\text { Sweden and Ohio) }\end{array}$ & $\begin{array}{l}4 \text { December } \\
2016\end{array}$ & No & No GC mentioned or offered & [57] \\
\hline \multicolumn{6}{|c|}{ 2. Includes reference to external GC services } \\
\hline 23andMe & $\begin{array}{l}\text { USA (we accessed } \\
\text { the site for British } \\
\text { customers) }\end{array}$ & $\begin{array}{l}4 \text { December } \\
2016\end{array}$ & No & $\begin{array}{l}\text { No GC offered, but GC mentioned, and customers } \\
\text { are advised to contact local 'counseling resources', } \\
\text { for example. the Association of Genetic Nurses } \\
\text { and Counsellors in the UK 'if you are concerned'. } \\
\text { This is the incorrect way to access GC in the UK }\end{array}$ & [58] \\
\hline \multicolumn{6}{|c|}{ 3. Health professional advice is available } \\
\hline $\begin{array}{l}\text { Genetic } \\
\text { Health }\end{array}$ & UK & $\begin{array}{l}4 \text { December } \\
2016\end{array}$ & Yes & $\begin{array}{l}\text { Offers pre- and post-consultation support with } \\
\text { a 'genetic-trained advisor' (but not labeled as } \\
\text { someone specialist in GC) }\end{array}$ & [47] \\
\hline \multicolumn{6}{|c|}{ 4. Post-test GC is offered } \\
\hline Veritas & $\begin{array}{l}\text { USA, China, } \\
\text { Luxembourg }\end{array}$ & $\begin{array}{l}4 \text { December } \\
2016\end{array}$ & Yes & $\begin{array}{l}\text { Offers GC post-test with a board certified genetic } \\
\text { counselor (but only for US customers) }\end{array}$ & [52] \\
\hline $\begin{array}{l}\text { Gene by } \\
\text { Gene }\end{array}$ & USA & $\begin{array}{l}4 \text { December } \\
2016\end{array}$ & Yes & $\begin{array}{l}\text { Offers GC post-test with a board certified } \\
\text { genetic counselor (but appears to be only for US } \\
\text { customers) }\end{array}$ & [51] \\
\hline $\begin{array}{l}\text { Sure } \\
\text { Genomics }\end{array}$ & USA & $\begin{array}{l}4 \text { December } \\
2016\end{array}$ & Yes & $\begin{array}{l}\text { Offers 1-h post-test GC with a board certified } \\
\text { genetic counselor (but appears to be only for US } \\
\text { customers) }\end{array}$ & [59] \\
\hline
\end{tabular}

\section{Future perspective}

When speculating on a future perspective about how the DTCGT field will evolve over the next 5-10 years, we anticipate that, given reducing costs of sequencing and increased application of sequencing in a clinical setting, the commercial market has the potential to grow exponentially. If recommendations from genetic health professionals and their professional bodies are heeded, then there is an urgent need to train a whole workforce of industry genetic counselors to meet the demand for jobs with DTCGT companies. However, despite recommendations to incorporate genetic counseling we suspect that companies may not do this in reality until they receive customer pressure to do so. As DTCGT becomes more easily available and more customers access it, we feel that it will not be long before cases emerge of customers experiencing tangible psychological damage from the results of tests linked to serious, life-threatening conditions. Take, for example, a healthy customer who has a DTC clinical exome done 'for curiosity'. The results reveal a variant of uncertain significance in a breastovarian cancer gene; the customer sees 'breast-ovar- ian gene' and mistakenly believes that she needs to have breast screening together with a discussion of risk-reducing mastectomy. As the majority of nongenetics health professionals have not yet had training in genomics, it is distinctly possible that the radiologist and breast surgeon she approaches may also not appreciate that a variant of uncertain significance does not need clinical action. It is easy to see how a misinterpreted result may lead to unnecessary screening and possible surgery. The consequences of this from both, a psychological and a physical perspective, are obvious. Involving a genetic counselor in the DTC process could have alleviated all of this.

We suggest that much more empirical research is needed to explore, over time, what the longterm psychosocial impact is, particularly for DTC customers who receive a 'high-risk' result relating to serious potentially life-threatening conditions. Given that such customers have elected to buy their tests outside of a healthcare service, there is no 'system' that they belong to - so finding them (to ask if they need support or to gather their views on their experience) is difficult without involving the DTCGT companies 
themselves. Another consequence of not being part of a healthcare system is that they have no continuity of care for themselves or other possible at-risk family members. Any long-term psychological or clinical follow-up would be at the discretion and responsibility of the DTCGT company, and yet such companies have no vested interest in discovering whether their tests are causing psychological or physical harm. More research is needed, by independent researchers, on the beneficial and harmful consequences of high-risk test results. Such researchers will need to think creatively about how they will access DTCGT customers and any research they conduct should be longitudinal, so that changing attitudes can be captured. In addition to this, the 'impact of the test' has potentially far reaching consequences for the family that extend beyond the individual tested. Thus, research should also cover: if and how customers share their results with their biological relatives (and how this is received), what the impact has been on their own clinical management (and the costs of this) and whether they have been on the receiving end of any discrimination as a result of the test.

Finally, although we are offering mainly a European perspective, it is likely that our discussion points are relevant to a non-European setting and we encourage debate and exploration of the nuances surrounding this (Table 1).

Financial \& competing interests disclosure This work has benefited greatly from involvement of the authors in the COST Action IS1303 "Citizen's Health through public-private Initiatives: Public health, Market and Ethical perspectives" (CHIP ME), especially the activities within the scope of Working Group 2. Á Mendes has worked on this theme while benefiting from a Short-Term Scientific Mission grant in the context of CHIP ME, in the Center for Research Ethics and Bioethics, Uppsala University. Á Mendes is supported by a postdoctoral fellowship from FCT - The Portuguese Foundation for Science and Technology (SFRH/BPD/88647/2012). CM Benjamin is supported by a Guild Fellowship at the University of Central Lancashire. HC Howard is supported by Swedish Foundation for Humanities and Social Science under grant M13-0260:1), the Biobanking and Molecular Resource Infrastructure of Sweden (BBMRI.se) and the BBMRI-ERIC. A Middleton is supported by core Wellcome funding via Connecting Science at the Wellcome Genome Campus, Cambridge, Wellcome grant reference: 206194/Z/17/Z. C Benjamin has sessional employment with GeneHealth UK (British private genetic testing company). The authors have no other relevant affiliations or financial involvement with any organization or entity with a financial interest in or financial conflict with the subject matter or materials discussed in the manuscript apart from those disclosed.

No writing assistance was utilized in the production of this manuscript.

\section{Open access}

This work is licensed under the Attribution-NonCommercial-NoDerivatives 4.0 Unported License. To view a copy of this license, visit http://creativecommons.org/licenses/bync-nd/4.0/

\section{Executive summary}

\section{Setting the scene}

- Direct-to-consumer genetic testing (DTCGT) for disease ranges from well-validated diagnostic and predictive tests to 'research' results conferring increased risks.

- While being targeted at public curious about their health, they are also marketed for use in reproductive decision-making or management of disease.

- By virtue of being 'direct-to-consumer' much of this testing bypasses traditional healthcare systems.

Genetic counseling within the DTCGT market

- "A genetics expert such as a certified medical geneticist or a genetic counselor should be available to help the consumer determine, for example, whether a genetic test should be performed and how to interpret test results in light of personal and family history" (American College of Medical Genetics).

- "Direct-to-consumer genetic testing and the advertisement of genetic tests of unproven benefit or without adequate independent genetic counseling are in opposition to the professional standards the European Society of Human Genetics sustains" (European Society Human Genetics).

- Genetic counselors have expertise in the management of genetic disease, what health screening is appropriate, and more recently they are becoming skilled in variant interpretation.

- Genetic counselors are also the healthcare professionals who primarily focus on the psychosocial and family communication issues that may arise from genetic (i.e., shared) information.

- DTCGT companies should make genetic counseling available, pre- as well as post-test.

Discussion

- While we do not advocate that mandatory genetic counseling should gate-keep access to DTCGT, if the testing process has the potential to cause psychological distress, then companies have a responsibility to provide support and should not rely on traditional healthcare systems to pick up the pieces. 


\section{References}

Papers of special note have been highlighted as:

- of interest

1 Giovanni MA, Fickie MR, Lehmann LS et al. Health-care referrals from direct-to-consumer genetic testing. Genet. Test. Mol. Biomarkers 14(6), 817-819 (2010).

2 Cornel MC, van El CG, Borry P. The challenge of implementing genetic tests with clinical utility while avoiding unsound applications. J. Community Genet. 5(1), 7-12 (2014).

3 Hogarth S, Javitt G, Melzer D. The current landscape for direct-to-consumer genetic testing: legal, ethical, and policy issues. Annu. Rev. Genomics Hum. Genet. 9, 161-182 (2008).

4 Slokenberga S. Direct-to-consumer genetic testing: changes in the EU regulatory landscape. Eur. J. Health Law 22(5), 463-480 (2015).

5 Patch C, Sequeiros J, Cornel MC. Direct to consumer genetic tests. Eur. J. Hum. Genet. 17(9), 1204 (2009).

6 Burton A. Are we ready for direct-to-consumer genetic testing? Lancet Neurol. 14(2), 138-139 (2015).

7 Middleton A. Communication about DTC testing: commentary on a 'family experience of personal genomics'. J. Genet. Couns. 21(3), 392-398 (2012).

8 Howard HC, Knoppers BM, Borry P. Blurring lines. The research activities of direct-to-consumer genetic testing companies raise questions about consumers as research subjects. EMBO Rep. 11(8), 579-582 (2010).

9 Niemiec E, Howard HC. Ethical issues in consumer genome sequencing: use of consumers' samples and data. Appl. Transl. Genom. 8, 23-30 (2016).

10 McGrath SP, Coleman J, Najjar L, Fruhling A, Bastola DR. Comprehension and data-sharing behavior of direct-toconsumer genetic test customers. Public Health Genomics 19(2), 116-124 (2016).

11 Brett GR, Metcalfe SA, Amor DJ, Halliday JL. An exploration of genetic health professionals' experience with direct-to-consumer genetic testing in their clinical practice. Eur. J. Hum. Genet. 20(8), 825-830 (2012).

12 BSGM. Direct to consumer genetic testing - guidelines from the British Society of Genetic Medicine. www.genomicmedicine.org/direct-to-consumer-genetic

- Demonstrates, from the professional body that represents clinical geneticists, genetic counselors and clinical scientists in the UK, the concerns they have about the impact of direct-to-consumer genetic testing (DTCGT).

13 Fears R, ter Meulen V. The perspective from EASAC and FEAM on direct-to-consumer genetic testing for healthrelated purposes. Eur. J. Hum. Genet. 21(7), 703-707 (2013).

14 McGuire AL Burke W. An unwelcome side effect of directto-consumer personal genome testing: raiding the medical commons. JAMA 300(22), 2669-2671 (2008).

15 Marteau TM, French DP, Griffin SJ et al. Effects of communicating DNA-based disease risk estimates on risk-reducing behaviours. Cochrane Database Syst. Rev. (10), Cd007275 (2010).
16 Bloss CS, Wineinger NE, Darst BF, Schork NJ, Topol EJ. Impact of direct-to-consumer genomic testing at long term follow-up. J. Med. Genet. 50(6), 393-400 (2013).

17 Dohany L, Gustafson S, Ducaine W, Zakalik D. Psychological distress with direct-to-consumer genetic testing: a case report of an unexpected BRCA positive test result. J. Genet. Couns. 21(3), 399-401 (2012).

- Demonstrates that a direct-to-consumer genetic test result for breast/ovarian cancer led to extreme psychological distress for a customer. Their psychological needs were not met by the direct-to-consumer company and had to be picked up by external healthcare providers.

18 Mardis ER, Lunshof JE. A focus on personal genomics. Pers. Med. 6(6), 603-606 (2009).

19 Hawkins AK, Ho A. Genetic counseling and the ethical issues around direct to consumer genetic testing. J. Genet. Couns. 21(3), 367-373 (2012).

20 Hogarth S. Myths, misconceptions and myopia: searching for clarity in the debate about the regulation of consumer genetics. Public Health Genomics 13(5), 322-326 (2010).

21 Corpas M. A family experience of personal genomics. J. Genet. Couns. 21(3), 386-391 (2012).

22 Kalokairinou L, Howard H, Borry P. Direct-toconsumer genetic testing. Wiley Online Library, eLS. doi:10.1002/9780470015902.a0025181 (2014) (Epub ahead of print).

23 ESHG. Statement of the European Society Human Genetics on direct-to-consumer genetic testing for health-related purposes. Eur. J. Hum. Genet. 18, 1271-1273 (2010).

- Provides European guidance on DTCGT and recommends that genetic counseling is provided by DTCGT companies for their customers.

24 Jordens CF, Kerridge IH, Samuel GN. Direct-to-consumer personal genome testing: the problem is not ignorance - it is market failure. Am. J. Bioeth. 9(6-7), 13-15 (2009).

25 Harris A, Kelly SE, Wyatt S. Counselling customers: emerging roles for genetic counselors in the direct-toconsumer genetic testing market. J. Genet. Couns. 22(2), 277-288 (2013).

26 ACMG. Direct-to-consumer genetic testing: a revised position statement of the American College of Medical Genetics and Genomics. Genet. Med. 18(2), 207-208 (2016).

- Provides American guidance on DTCGT and recommends that genetic counseling is provided by DTCGT companies for their customers.

27 Darst BF, Madlensky L, Schork NJ, Topol EJ, Bloss CS. Perceptions of genetic counselling services in direct-toconsumer personal genomic testing. Clin. Genet. 84(4), 335-339 (2013).

- Indicates that DTCGT customers, who seek out genetic counseling post-test, do indeed find this helpful in terms of informational content and support.

28 ASHG (American Society of Human Genetics Ad Hoc Committee on Genetic Counselling). Genetic counselling. Am. J. Hum. Genet. 27, 240-242 (1975). 
R, Biesecker BB, Bennett RL et al. A new definition of genetic counselling: National Society of Genetic Counselors' Task Force report. J. Genet. Couns. 15(2), 77-83 (2006).

Skirton H, Lewis C, Kent A, Coviello DA. Genetic education and the challenge of genomic medicine: development of core competences to support preparation of health professionals in Europe. Eur. J. Hum. Genet. 18(9), 972-977 (2010).

31 GCRB (Genetic Counsellor Registration Board, UK and ROI) What is genetic counselling? www.gcrb.org.uk/public

32 Paneque M, Moldovan R, Cordier C et al. Development of a registration system for genetic counsellors and nurses in health-care services in Europe. Eur. J. Hum. Genet. 24(3), 312-314 (2016).

33 Resta R. What is genetic counselling? https://thednaexchange.com/2016/09/11/what-is-genetic

34 Cordier C, Lambert D, Voelckel MA, Hosterey-Ugander U, Skirton H. A profile of the genetic counsellor and genetic nurse profession in European countries. J. Community Genet. 3(1), 19-24 (2012).

35 Waltman L, Runke C, Balcom J et al. Further defining the role of the laboratory genetic counselor. J. Genet. Couns. 25(4), 786-798 (2016).

36 McCarthy Veach P, LeRoy B, Bartels D. Overview on genetic counselling: history of the profession and methods of practice. In: Facilitating the Genetic Counseling Process: A Practice Manual. McCarthy Veach P, LeRoy B, Bartels D (Eds). Springer, NY, USA (2003).

37 Kessler S. Psychological aspects of genetic counselling IX: teaching and counselling. J. Genet. Couns. 6(3), 287-295 (1997).

38 Cohen SA, Marvin ML, Riley BD, Vig HS, Rousseau JA, Gustafson SL. Identification of genetic counselling service delivery models in practice: a report from the NSGC Service Delivery Model Task Force. J. Genet. Couns. 22(4), 411-421 (2013).

39 Benjamin CC, Houghton C, Foo C et al. A prospective cohort study assessing clinical referral management and workforce allocation within a UK regional medical genetics service. Eur. J. Hum. Genet. 23(8), 996-1003 (2015).

Skirton H, Cordier C, Ingvoldstad C, Taris N, Benjamin C. The role of the genetic counsellor: a systematic review of research evidence. Eur. J. Hum. Genet. 23(4), 452-458 (2015).

41 Hennen L, Sauter A, Van Den Cruyce E. Direct to consumer genetic testing: insights from an Internet Scan. New Genet. Soc. 29(2), 167-186 (2010).
42 Gene Planet. www.geneplanet.com/about-us/partners.html

43 Gene Planet. www.geneplanet.com/genetic-analysis/the-process-of-dna

44 Gene Planet. www.geneplanet.com/terms-and-conditions.html

45 23andMe. https://blog.23andme.com/health-traits

46 23andMe. www.23andme.com/about/tos

47 Genetic Health. www.genetic-health.co.uk

48 Genetic Counsellor Registration Board. www.gcrb.org.uk

49 Eurogentest (2009). Recommendations for genetic counselling related to genetic testing. www.eurogentest.org/fileadmin/templates/eugt/pdf

50 Genetic Health. www.genetic-health.co.uk/dna-test-services.htm

51 Gene by Gene. https://gxg.genebygene.com/carrier-screening

52 Veritas. www.veritasgenetics.com/mybrca

53 Human Genetics Commission. A Common Framework of Principles for Direct-to-Consumer Genetic Testing Services. Human Genetics Commission, London, UK (2010). www.cellmark.co.uk/pdfs/HGCprinciples.pdf

54 Davey A, Rostant K, Harrop K, Goldblatt J, O’Leary P. Evaluating genetic counselling: client expectations, psychological adjustment and satisfaction with service. J. Genet. Couns. 14(3), 197-206 (2005).

55 McCarthy Veach P, LeRoy B, Bartels D. Coming full circle: a reciprocal-engagement model of genetic counselling practice. J. Genet. Couns. 16(6), 713-728 (2007).

56 McLeod R, Crawford D, Booth K. Patient's perceptions of what makes genetic counselling effective: an interpretative phenomenological analysis. J. Health Psychol. 7(2), 145-156 (2002).

57 Gene Planet. www.geneplanet.com

58 23andMe. www.23andme.com

59 Sure Genomics. www.suregenomics.com 